\title{
miR-326 inhibits the progression of papillary thyroid carcinoma by targeting MAPK1 and ERBB4
}

\author{
F. R. NIE*, Q. X. LI, H. F. WEI, Y. MA \\ Department of Endocrinology, Shenzhen Longhua District Central Hospital, Shenzhen, Guangdong, China \\ ${ }^{*}$ Correspondence: FurongNiedfg@163.com
}

Received July 31, 2019 / Accepted October 8, 2019

\begin{abstract}
Papillary thyroid carcinoma (PTC) is the prevalent histotype of thyroid cancer, with increasing incidence worldwide. MicroRNAs (miRNAs) could play an important role in the development and progression of human cancers. Interestingly, miR-326 was validated as one of the downregulated miRNAs in PTC. Therefore, it is necessary to research the function of miR-326 involved in the progression of PTC. In the current study, we detected the downregulation of miR-326 in PTC tissues and cell lines. The miR-326 overexpression or knockdown was conducted in TPC-1 or HTh83 PTC cells. miR-326 mimics decreased the proliferation, clone formation ability and caused G1-phase accumulation. In addition, the reduction of migration and invasion abilities was induced by miR-326 mimics. Western blot analysis showed that the cells with miR-326 mimics exhibited the inhibition of vimentin and N-cadherin, as well as enhancement of E-cadherin. Importantly, miR-326 could directly target mitogen activated protein kinase 1 (MAPK1) and epidermal growth factor receptor 4 (ERBB4). MAPK1 or ERBB4 overexpression rescued the effects of miR-326 on proliferation, migration, and invasion in PTC cells. Notably, miR-326 reduced tumorigenesis in vivo, including the decrease of tumor volume and weight, suppression of Ki-67, N-cadherin, MAPK1 and ERBB4. In all, these results might provide a new therapeutic target for the diagnosis of PTC.
\end{abstract}

Key words: miR-326, MAPK1, ERBB4, papillary thyroid carcinoma

Thyroid cancer is the most common malignant endocrine tumor, with increasing incidence worldwide [1-4]. Papillary thyroid carcinoma (PTC) is the prevalent histotype of thyroid cancer, accounting for $80 \%$ of thyroid malignancies $[5,6]$. The overall survival of PTC is approximately $97 \%$. However, there is a minority of patients with recurrent disease and distant metastases to occur [7-10]. Up to date, the treatment options for PTC are identified, such as radioactive iodine ablation, surgery, and thyroid hormone replacement [11]. Although the therapeutic strategies are applied to PTC, the mechanism of PTC treatment is still unclear.

MicroRNAs (miRNAs), 18-24 nucleotides, are singlestranded non-coding RNA molecules [12, 13]. miRNAs can target mRNAs in the 3'-untranslated region (UTR) and regulate mRNA degradation and translational suppression [14-16]. Importantly, miRNAs have been reported to play an important role in the development and progression of human cancers, including gastric cancer [17], pancreatic ductal adenocarcinoma [18], nasopharyngeal carcinoma
[19], and glioma [20]. Interestingly, miR-326 was validated as one of the downregulated miRNAs in PTC and related to the progression of PTC [21]. Therefore, the function of miR-326 in PTC needs to be explored.

Mitogen activated protein kinase 1 (MAPK1) protein is important in the MAPK1 pathway and it can regulate cellular activities and tumor development in many human diseases [22]. For instance, MAPK1 was found to be involved in cell proliferation and tumor growth in colorectal cancer [23]. The individual mature $\mathrm{Hrg}$ isoforms are reported to be natural ligands for epidermal growth factor receptor 4 (ERBB4) [24, 25]. Previous studies have shown that ERBB4 activation was related to the proliferation and tumorigenicity in glioblastoma [26]. Interestingly, MAPK1 and ERBB4 were reported to participate in PTC $[27,28]$. In our study, we indicated that miR-326 could bind with MAPK1 or ERBB4. The miR-326 showed its function in the development of PTC through directly targeting MAPK1 and ERBB4. A possible link of miR-326 to PTC can be deduced from this study, which adds to our understanding of PTC treatment. 


\section{Patients and methods}

Tissue samples collection. The tumor tissues and paracancerous tissues of 60 patients with PTC were collected from Shenzhen Longhua District Central Hospital from March 2013 to January 2016. Patients gave written informed consent. For the samples, two separate pathologists reviewed all histologic sections to identify tumor grade and distant metastasis according to the American Joint Commission on Cancer 7 th edition. The study was approved by Shenzhen Longhua District Central Hospital and the World Medical Association Declaration of Helsinki.

Cell culture and transfection. Human normal thyroid cell line Nthy-ori 3-1, human PTC cell lines (TPC-1, BCPAP, CGTH-W-3, and HTh83) and HEK293 cell line were harvested from ATCC. They were grown in DMEM medium containing $10 \%$ fetal bovine serum (FBS) at $37^{\circ} \mathrm{C}$ in the presence of $5 \% \mathrm{CO}_{2} .4 \times 10^{4} \mathrm{TPC}-1$ or HTh 83 cells were seeded on 6-well plates, respectively. The TPC-1 cells were transfected with miR-326 NC (negative control) or miR-326 mimics, whereas HTh83 cells were transfected with miR-326 NC or miR-326 inhibitor via the Lipofectamine 2000 (Thermo Fisher Scientific, Waltham, MA, USA).

Quantitative real-time PCR. Total RNA was extracted using Trizol reagent (Takara, Shiga, Japan). cDNA synthesis was carried out. The miR326 expression level was determined with the SYBR Green kit (Applied Biosystems, Foster City, USA). U6 was the internal control. The data were computed using the $2^{-\triangle \mathrm{CT}}$ method. The primers are listed in Table1.

In situ hybridization (ISH). The Nthy-ori 3-1, TPC-1, BCPAP, CGTH-W-3 or HTh83 cells were fixed in $4 \%$ polyoxymethylene, embedded with paraffin and then cut into $4 \mu \mathrm{m}$ sections. The sections were deparaffinized and analyzed. miR-326 was used as a probe in the present study. The primary antibody, anti-digoxigenin-alkaline phosphatase Fab fragments (1:800, Roche Diagnostics Gmbh, Mannheim, Germany), was used for signal detection. Subsequently, nitro blue tetrazolium/5-bromo-4-chloroindol-3-yl-phosphate solution (Roche Diagnostics GmbH, Mannheim, Germany) antibody was used to incubate the sections. The images were captured under a microscope.

Cell proliferation analysis. Cell proliferation was assessed by a CCK- 8 assay (Beyotime, Jiangsu, China). TPC-1 and HTh83 cells were seeded in a 96-well plate. After being transfected for $0 \mathrm{~h}, 24 \mathrm{~h}, 48 \mathrm{~h}$, and $72 \mathrm{~h}$, the cells were incubated with $10 \mu \mathrm{l}$ CCK-8. After the incubation for $4 \mathrm{~h}$, the optical density (OD) was assayed at the wavelength of $450 \mathrm{~nm}$.

Table 1. Primer sequences.

\begin{tabular}{ll}
\hline GENE & Primer sequences (5'-3') \\
\hline miR-326 & F: ACTGTCCTTCCCTCTGGGC \\
& R: AATGGTTGTTCTCCACTCTCTCTC \\
U6 & F: ATTGGAACGATACAGAGAAGATT \\
& R: GGAACGCTTCACGAATTTG \\
\hline
\end{tabular}

Colony formation assay. Cells were seeded in 6-well plates and grown for two weeks. They were fixed and stained with crystal violet for $15 \mathrm{~min}$ when most of the colonies had expanded to more than 100 cells. Finally, the photographs were obtained and the colonies were calculated.

Cell cycle analysis. The transfected cells were harvested, fixed in $70 \%$ ethanol at $4{ }^{\circ} \mathrm{C}$ overnight, and washed with PBS. Then, $400 \mu \mathrm{l}$ of PI solution and $100 \mu \mathrm{l}$ of RNase A were used to treat the cells. After incubation for $30 \mathrm{~min}$ in a dark room, the cell cycle was determined by flow cytometry.

Cell invasion and migration assays. For cell invasion or migration assays, the membrane of the chamber was coated with Matrigel or without Matrigel. Briefly, cells were harvested after transfection and $2 \times 10^{4}$ cells were seeded in the upper Matrigel-coated chamber, whereas the bottom of the chamber was filled with medium containing 10\% FBS. After $24 \mathrm{~h}$, cells were fixed and stained with $0.2 \%$ crystal violet for 30 minutes. At last, the assays were performed and the number of cells was obtained under a microscope.

Western blot analysis. Total proteins were lysed using RIPA buffer (CWBIO, Beijing, China). The BCA Protein Assay Reagent (Sangon Biotech, Shanghai, China) was used for protein concentration analysis. Then, equivalent amounts of protein $(30-50 \mu \mathrm{g})$ were separated using $10 \%$ SDS-PAGE gels and transferred onto PVDF membranes. The membranes were subsequently blocked in a blocking buffer and incubated with anti-vimentin (1:100, Santa Cruz Biotechnology, CA, USA), anti-N-cadherin antibodies (1:1000, Abcam, Cambridge, MA, UK), anti-E-cadherin (1:500, Abcam, Cambridge, MA, UK), anti-MAPK1 (1:500, Cell Signaling Technology, Danvers, MA, USA), anti-ERBB4 (1:500, Santa Cruz, Dallas, TX, USA), anti-Ki67 (1:1000, Abcam, Cambridge, MA, UK) and $\beta$-actin (1:1000, Cell Signaling Technology, Danvers, MA, USA) primary antibodies at $4{ }^{\circ} \mathrm{C}$ overnight. Then, the membranes were incubated with secondary antibodies at room temperature for $50 \mathrm{~min}$. An ECL system kit (MultiSciences, Hangzhou, China) was used to measure the signals. ImageJ software (NIH, Bethesda, MD, USA) was used for quantification of the protein bands.

Tumor xenograft in nude mice. The 4-6 weeks female mice were obtained from Sippr-BK Laboratory Animal Co., Ltd. (Shanghai, China). The mice were randomly divided into 2 groups ( $n=6 /$ group). Mice were then subcutaneously implanted with $1 \times 10^{6}$ cells transfected with $\mathrm{NC}(\mathrm{Lv}-\mathrm{NC})$ or miR-326 overexpression (Lv-miR-326). Tumor volume was recorded every seven days. The observation lasted for 28 days, the mice were sacrificed, and tumor tissues were weighed and photographed. The gross tumor volume was detected based on the following formula: $\mathrm{V}=0.5 \times \mathrm{L} \times \mathrm{W}^{2}$. The experimental protocol was carried out in compliance with the Guide for the Care and Use of Laboratory Animals and approved by the Animal Ethical and Welfare Committee Approval No. GDY18011004.

Immunohistochemical analysis. The tumor tissues were fixed in $4 \%$ paraformaldehyde (PFA). Serial paraffin 
sections $(5 \mu \mathrm{m})$ of the tumor tissues were deparaffinized and rehydrated. The endogenous peroxidase activity and nonspecific binding of sections were blocked. Subsequently, the sections were incubated with monoclonal antibodies against Ki-67 (1:2000, Abcam, Cambridge, MA, UK), N-cadherin (1:300, Abcam, Cambridge, MA, UK), MAPK1 (1:200, Cell Signaling Technology, Inc., Danvers, MA, USA) and ERBB4 (1:100, Santa Cruz Biotechnology Inc., Santa Cruz, CA, USA) at $4^{\circ} \mathrm{C}$ overnight, and then incubated with secondary antibody (1:1500, Abcam, Cambridge, MA, UK). The signals were visualized with diaminobenzidine. Images were observed under a Nikon BX-51 light microscope.

Dual luciferase reporter assay. The wild-type and mutanttype MAPK1 or ERBB4 3'UTR sequences were amplified and cloned into pmirGLO luciferase reporter plasmids to generate MAPK1 WT, MAPK1 MUT, ERBB4 WT or ERBB4 MUT. The HEK923 cells were co-transfected with MAPK1 or ERBB4 luciferase reporter plasmids and miR-326 NC or miR-326 mimics via Lipofectamine 2000. After $48 \mathrm{~h}$ transfection, the luciferase activity was assayed via Dual Luciferase Reporter Assay System.
Statistical analysis. All results were analyzed with SPSS21.0 for Windows. The experiments were repeated at least three times. Student's two-tailed t-test was used for analysis. Data are reported as means $\pm \mathrm{SD}$. A p-value $<0.05$ was considered statistically significant.

\section{Results}

miR-326 had a low expression in PTC tissues and cell lines. The miR-326 expression was first measured in PTC tissues using quantitative real-time PCR. The results showed that miR-326 expression was repressed in PTC tissues compared with paracarcinoma tissues $(0.39$-fold, $\mathrm{p}<0.0001)$. Moreover, miR-326 expression was decreased in grade III-IV PTC tissues compared with grade I-II tissues (0.48-fold, $\mathrm{p}=0.0035)$, and it was also inhibited in metastatic tissues compared with non-metastatic tissues (0.63-fold, $\mathrm{p}=0.0374$ ) (Figure 1A). Next, ISH revealed that there was a lower miR-326 expression in PTC tissues compared with paracarcinoma tissues (Figure 1B). In addition, in PTC cell lines (HTh83, BCPAP, CGTH-W-3 and TPC-1), the level of
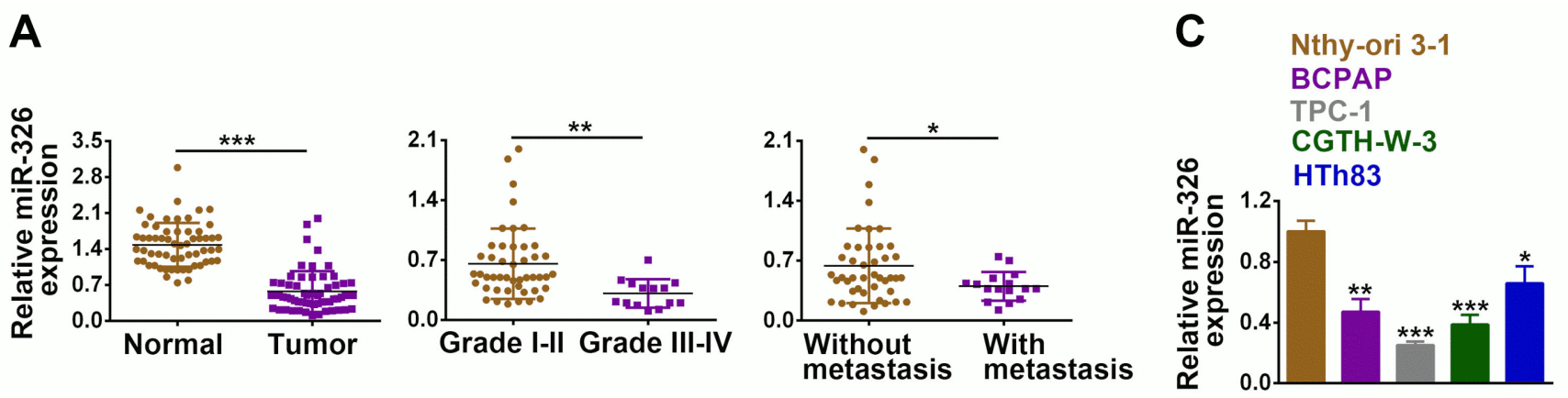

B

Patient \#1

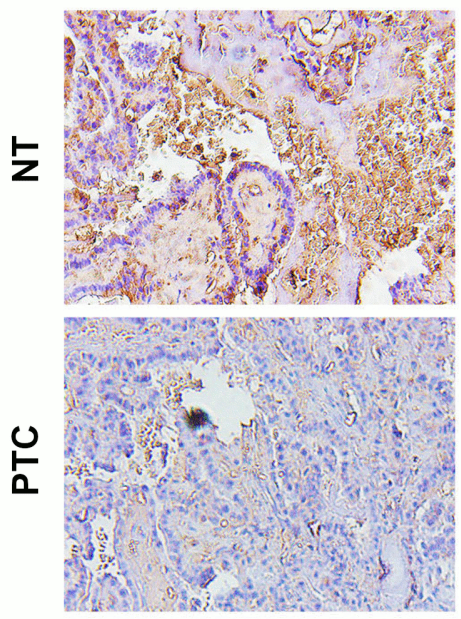

Patient \#2

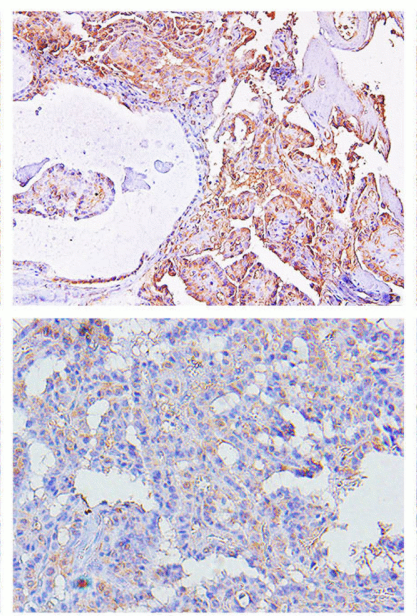

Patient \#3

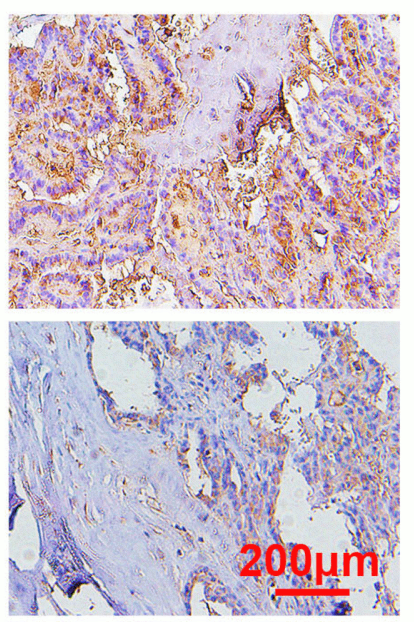

Figure 1. miR-326 had a low expression in PTC tissues and cell lines. A) miR-326 expression was analyzed by quantitative real-time PCR. B) miR-326 expression was measured with in situ hybridization. C) The expression level of miR-326 in PTC cell lines. ${ }^{*} \mathbf{p}<0.05,{ }^{* *} \mathbf{p}<0.01,{ }^{* * *} p<0.001$ 
miR-326 was the lowest in TPC-1 cells and the highest in HTh83 cells (Figure 1C). The data showed that miR-326 had a low expression in PTC tissues and cell lines.

miR-326 inhibited proliferation in PTC cells. We further examined whether miR-326 affected cell proliferation in PTC. The miR-326 was successfully overexpressed in TPC-1 cells $(118.96$-fold, $\mathrm{p}<0.0001)$ and knocked down in HTh83 cells (0.43-fold, $\mathrm{p}=0.0007$ ) (Figure 2A). CCK-8 assay demonstrated that miR-326 mimics decreased cell proliferation and miR-326 inhibitor increased cell proliferation (Figure 2B). Furthermore, miR-326 mimics repressed clone formation ability of TPC- 1 cells $(0.43$-fold, $\mathrm{p}=0.0003)$, whereas miR-326 inhibitor promoted clone formation ability of HTh83 cells (1.64-fold, $\mathrm{p}=0.0038$ ) (Figure 2C). miR-326 mimics caused G1-phase accumulation. However, miR-326 inhibitor reduced the percentage of G1 cells (Figure 2D). These findings indicated that miR-326 inhibited PTC cell proliferation.

miR-326 reduced migration and invasion in PTC cells. To determine the effect of miR-326 on migration and invasion in PTC cells, cell invasion and migration assays were carried out. Compared with the control group, TPC-1 cells with miR-326 mimics exhibited weaker migration (0.56-fold, $\mathrm{p}=0.0028)$ and invasion ( 0.43 -fold, $\mathrm{p}=0.0012)$ while $\mathrm{miR}-326$ inhibitor enhanced the abilities of migration (2.85-fold, $\mathrm{p}=0.001)$ and invasion $(2.51$-fold, $\mathrm{p}=0.001)$ (Figures $3 \mathrm{~A}, 3 \mathrm{~B}$ ). Moreover, vimentin, $\mathrm{N}$-cadherin and E-cadherin protein levels, which are related to migration and invasion, were examined with western blot analysis. The results indicated that miR-326 mimics inhibited vimentin (0.60-fold, $\mathrm{p}=0.00278$ ) and $\mathrm{N}$-cadherin (0.65-fold, $\mathrm{p}=0.00403)$, as well as enhanced E-cadherin (2.06-fold, $\mathrm{p}=0.00073$ ), whereas miR-326 inhibitor showed the reverse effect on these protein levels (Figure 3C). The data suggested that miR-326 reduced migration and invasion in PTC cells.

miR-326 directly targeted MAPK1 and ERBB4. We next predicted whether miR-326 could directly target MAPK1 and ERBB4, and the relative luciferase activities were significantly inhibited in HEK293 cells co-transfected with miR-326 mimics and MAPK1 WT (0.49-fold, $\mathrm{p}=0.0001)$ or ERBB4 WT (0.52-fold, $\mathrm{p}=0.0009)$. However, there was no effect when these cells were co-transfected with miR-326 mimics and MAPK1 MUT or ERBB4 MUT (Figure 4A). Importantly, quantitative real-time $\mathrm{PCR}$ revealed that decrease of MAPK1 (0.49-fold, $\mathrm{p}=0.0004)$ or ERBB4 (0.49-fold, $\mathrm{p}=0.0021$ ) level was assayed in TPC-1 cells with miR-326 mimics and increase of MAPK1 (1.94-fold, $\mathrm{p}=0.0019)$ or ERBB4 (3.11-fold, $\mathrm{p}<0.0001)$ level was determined in HTh83
A

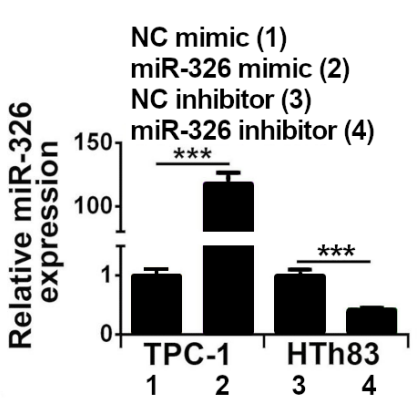

C

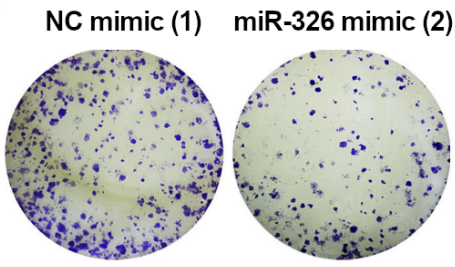

D

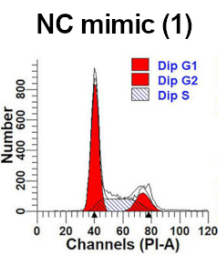

B

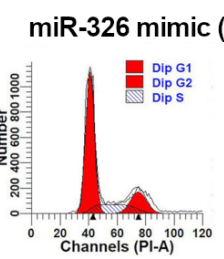

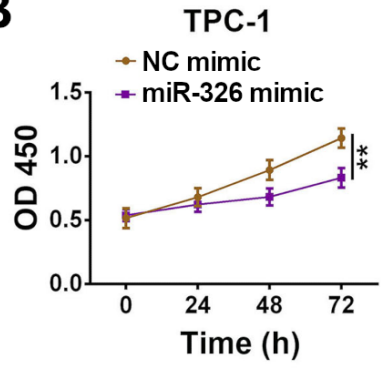
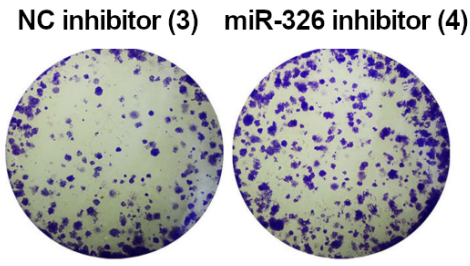

(2) NC inhibitor (3)

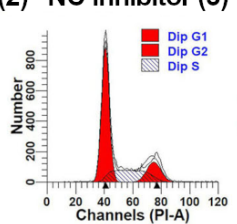

HTh83
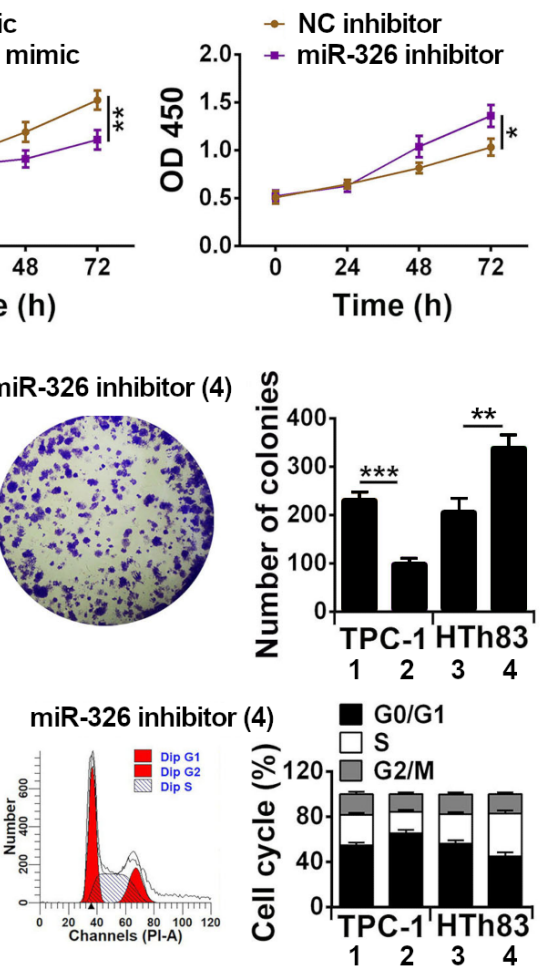

Figure 2. miR-326 inhibited proliferation in PTC cells. A) miR-326 expression was detected in TPC-1 cells transfected with miR-326 NC (1) or miR-326 mimics (2), as well as in HTh83 cells transfected with miR-326 NC (3) or miR-326 inhibitor (4) using quantitative real-time PCR. CCK-8 assay was conducted to determine cell proliferation (B). In addition, colony formation (C) and flow cytometric analysis of cell cycle (D) was examined. ${ }^{*} \mathbf{p}<0.05$, ${ }^{* *} \mathrm{p}<0.01,{ }^{* * *} \mathrm{p}<0.001$ 


\title{
A
}
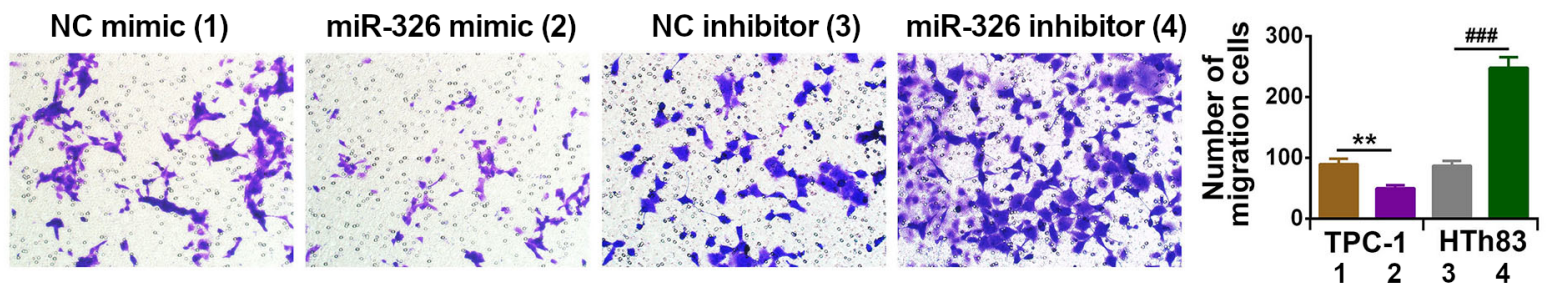

B

NC mimic (1)

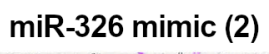

NC inhibitor (3)
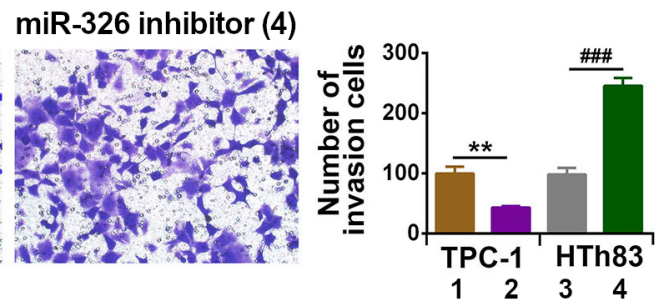

C
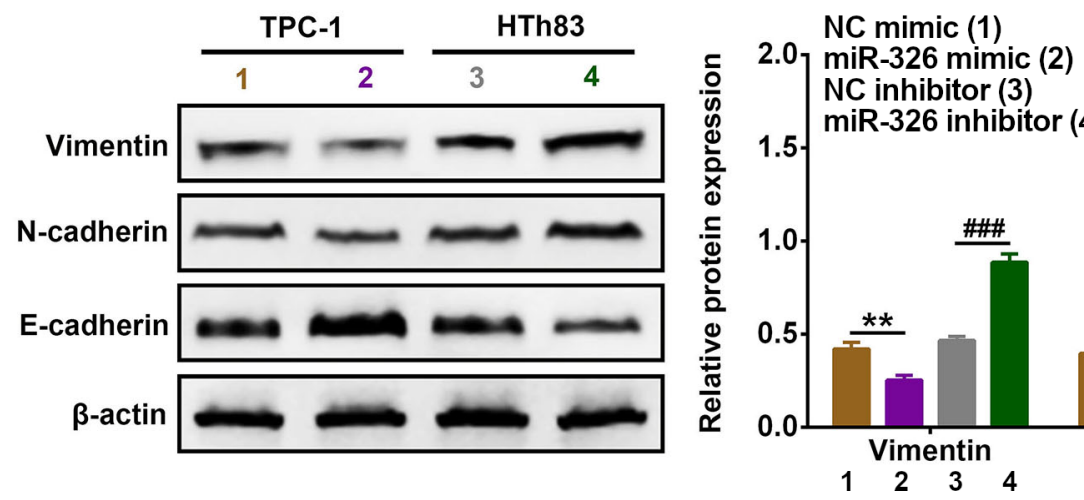

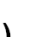

*** 
A
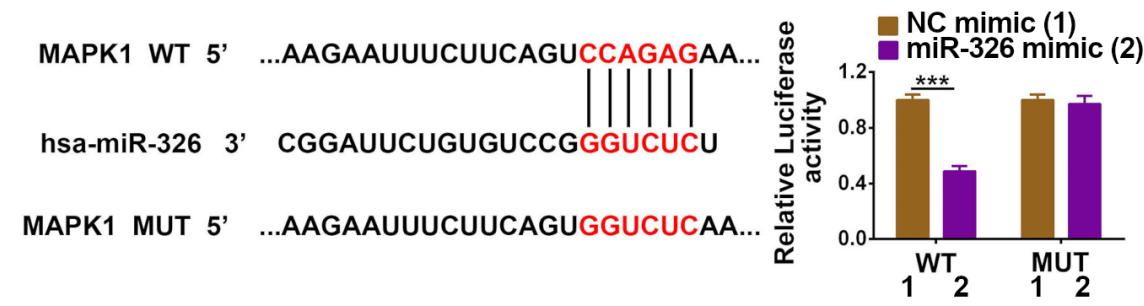

ERBB4 WT 5 , ...UAAAAUUUUUCUGaUCCCAgaga... hsa-miR-326 3, GACCUCCUUCCCGGGUCUCC

ERBB4 MUT 5, ...UAAAAUUUUUCUGAUCGgUCUCA...

B
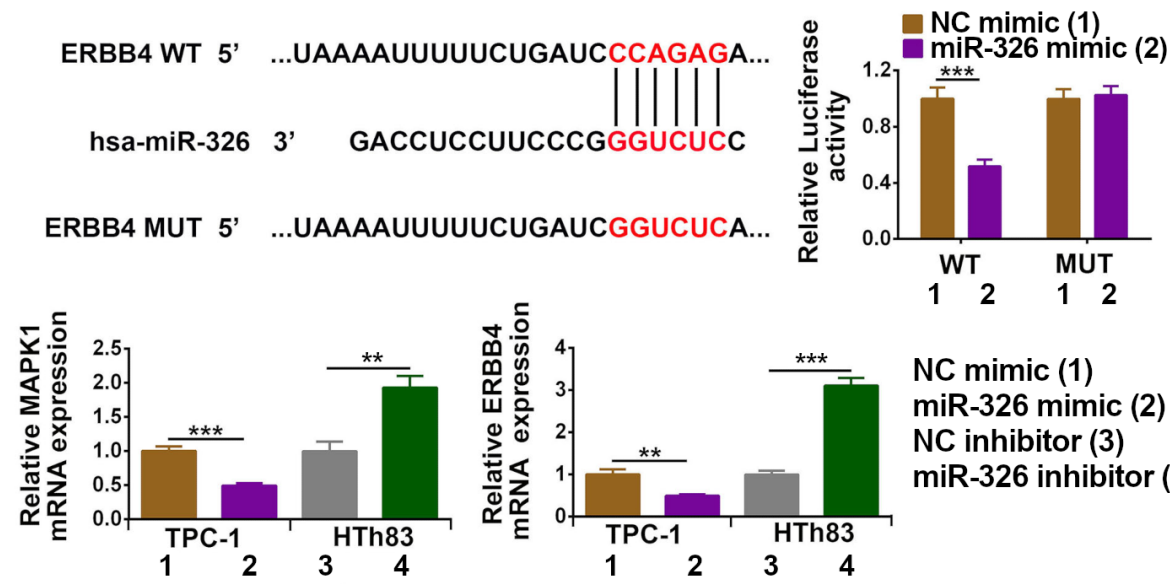

NC mimic (1)

miR-326 mimic (2)

NC inhibitor (3)

miR-326 inhibitor (4)
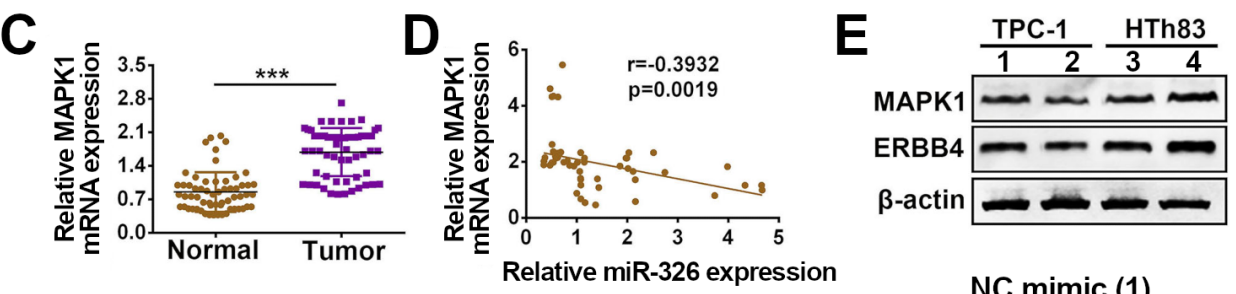

Relative miR-326 expression

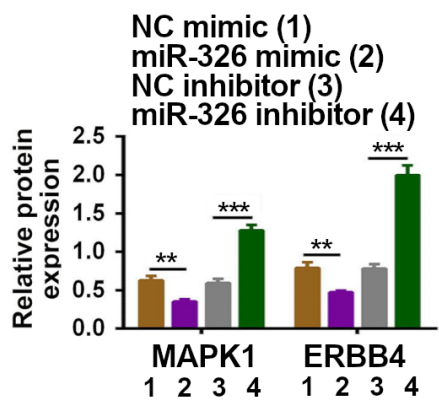

Figure 4. miR-326 directly targeted MAPK1 and ERBB4. A) The relative luciferase activity was detected via luciferase reporter assay. B, C) MAPK1 or ERBB4 expression was examined in PTC cells or tissues using quantitative real-time PCR. D) The relation between miR-326 and MAPK1 or ERBB4 was assayed. E) MAPK1 and ERBB4 protein levels were determined via western blot analysis. ${ }^{\star} p<0.05,{ }^{\star *} p<0.01,{ }^{* * *} p<0.001$

\section{Discussion}

In this study, a low miR-326 expression level was determined in PTC tissues. In order to explore the function of miR-326 in PTC cell lines, we performed miR-326 overexpression or knockdown in TPC-1 or HTh83 cells, respectively. Functional analyses indicated that miR-326 could inhibit proliferation, reduce clone formation ability and arrest the cell cycle in PTC cell lines. Moreover, miR-326 could play a negative role in migration and invasion. We also confirmed that MAPK1 or ERBB4 harvested the binding site of miR-326. The effects of miR-326 on proliferation, migration, and invasion could be restored by MAPK1 and ERBB4 in PTC cell lines. In addition, miR-326 was also demonstrated to suppress tumorigenesis in vivo. Therefore, we conclude that miR-326 can play an important role in the development of PTC.

Numerous studies revealed that miRNAs were associated with PTC. For example, miR-202-3p was found to be downregulated in PTC tissues, and to repress cell migra- 
A

B NC mimic miR-326 mimic
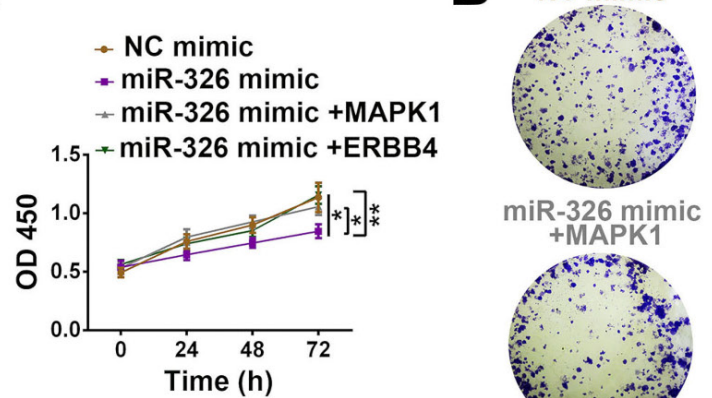
miR-326 mimic
+MAPK1
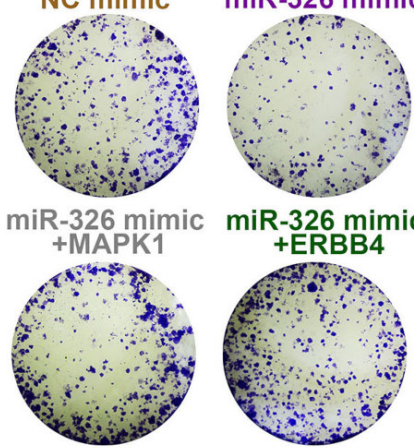

miR-326 mimic
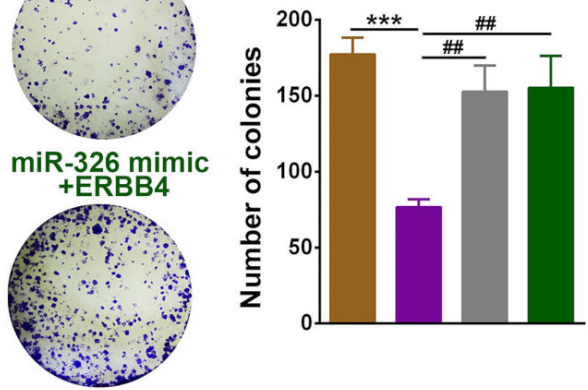

\section{C}
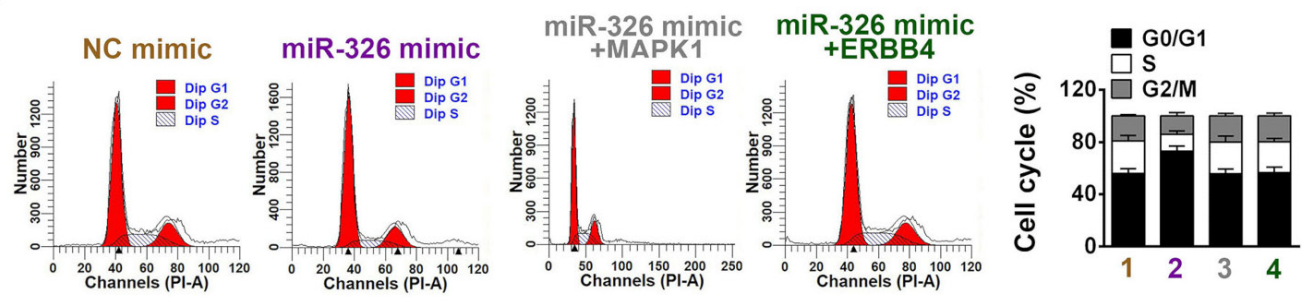

D

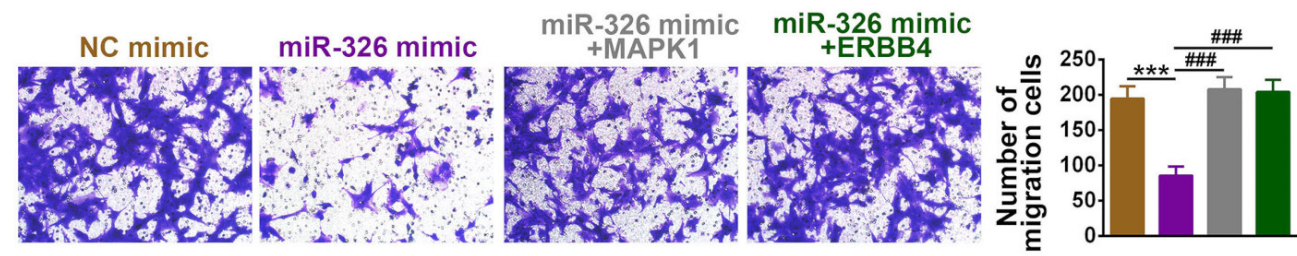

$\mathbf{E}$

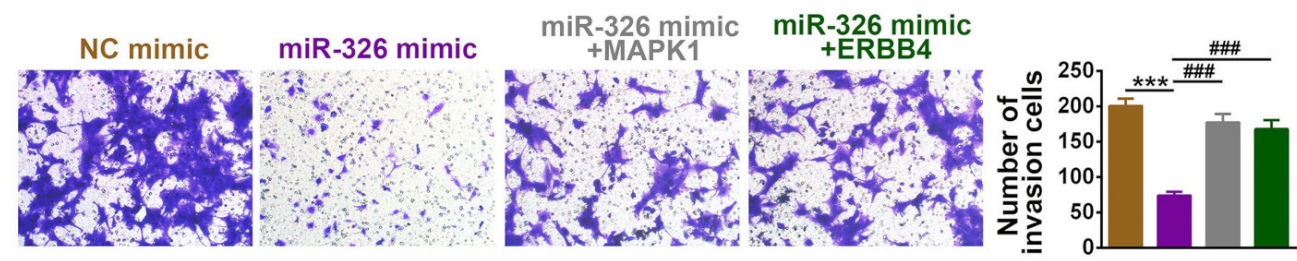

$\mathbf{F}$
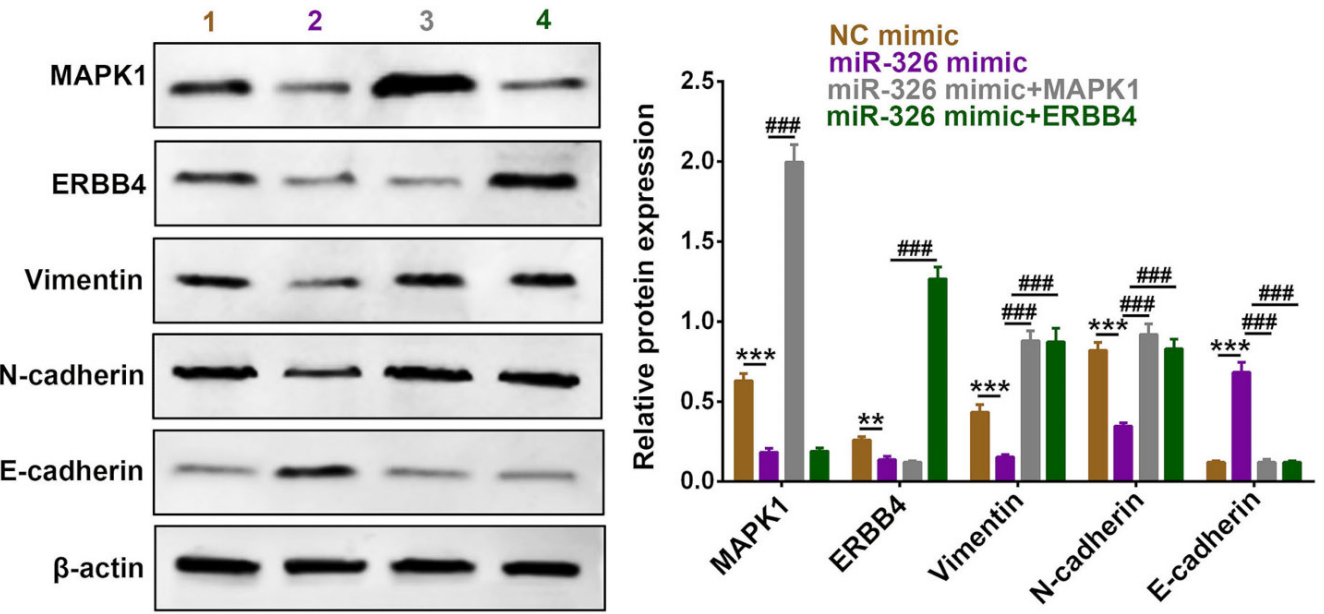

Figure 5. miR-326 inhibited proliferation, migration, and invasion by targeting MAPK1 and ERBB4 in PTC cells. A) CCK-8 assay determined cell proliferation. B) Clone formation ability was measured. C) Flow cytometer used to measure the cell cycle. D, E) Cell migration and invasion were examined with Trans-well assay. F) Western blot analysis determined MAPK1, ERBB4, vimentin, N-cadherin, and E-cadherin protein levels. ${ }^{* *} \mathbf{p}<0.01$, ${ }^{* * *} \mathrm{p}<0.001$ 
A
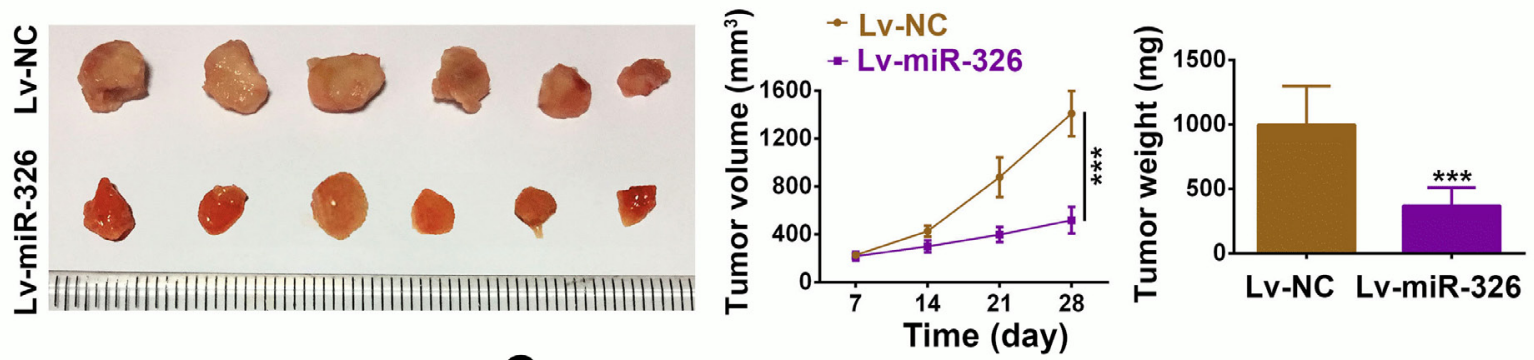

B

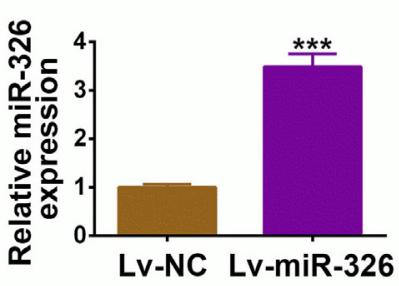

D

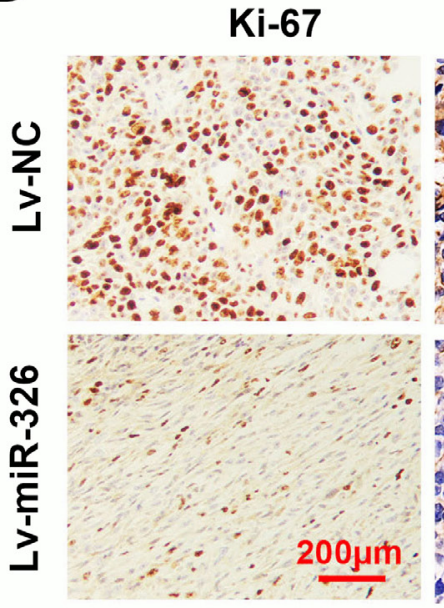

\section{C}
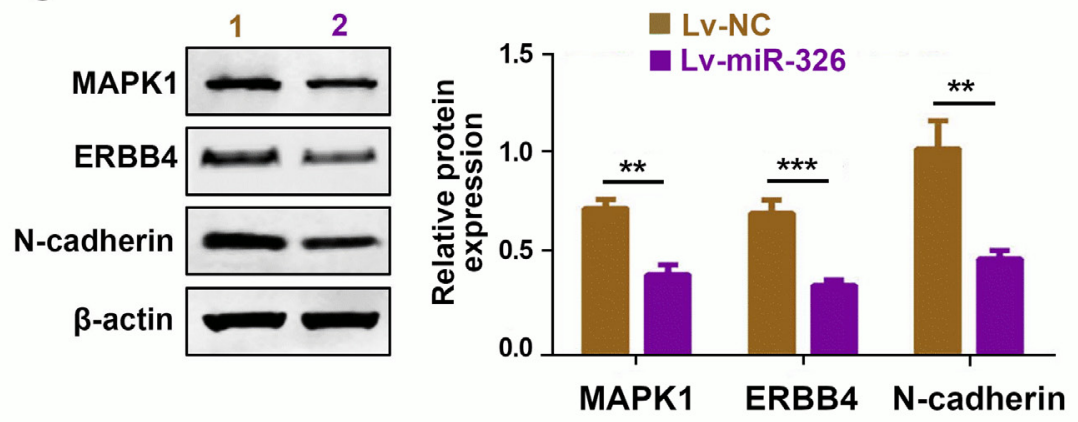

Figure 6. miR-326 inhibited tumorigenesis in vivo A) Tumor volume and weight were calculated. B) miR-326 expression was examined through quantitative real-time PCR. C) MAPK1, ERBB4, and N-cadherin protein levels were assayed via western blot analysis. D) The immunohistochemical analysis detected Ki-67, N-cadherin, MAPK1, and ERBB4. ${ }^{* *} \mathrm{p}<0.01,{ }^{* * *} \mathrm{p}<0.001$

tion as well as invasion in PTC [29]. Furthermore, enforced expression of miR-29a-3p could reduce cell growth, proliferation, and invasion in PTC [30]. Additionally, miR-128 was reported to be associated with the development of PTC and it could suppress the growth of PTC [31]. Moreover, miR-539 was identified as a tumor suppressor to affect the progression of PTC [32]. Consistent with the function of miRNAs, in our study, we proved that miR-326, as one of the miRNAs, was decreased in PTC tissues compared to adjacent normal tissues. The inhibition of the proliferation, clone formation ability, cell cycle, migration, and invasion was caused by miR-326 overexpression in PTC cell lines. Moreover,
miR-326 overexpression could also suppress tumorigenesis in vivo. Consistent with the existing studies, miR-326 could have an abnormal expression in various human cancers and negatively regulate the procession of tumors [33-35]. These findings can offer supporting evidence for the suppressive roles of miR-326 in PTC.

MAPKs, as a kind of protein kinases, have been reported to promote cell proliferation and survival in PTC $[36,37]$. Wang et al. showed that MAPK1 upregulation was useful for tumor growth promotion in thyroid cancer cells [22]. Importantly, previous studies indicated that miR-585 could suppress the proliferation and migration by targeting MAPK1 in gastric 
cancer [38]. Besides, ERBB4 was found to be reduced in PTC cells [39]. Li et al. discovered that miR-1273g-3p could affect proliferation, migration, and invasion via ERBB4 in LoVo cells [40]. Interestingly, our data verified that MAPK1 or ERBB4 were a direct and functional target of miR-326 in PTC cells. In addition, MAPK1 and ERBB4 could reverse the inhibition of proliferation, migration, and invasion induced by miR-326. These findings suggest that miR-326 can regulate the progression of PTC through targeting MAPK1 and ERBB4.

In conclusion, we demonstrated that miR-326 could function as a tumor suppressor in PTC. miR-326 overexpression could lead to the inhibition of progression in PTC by targeting MAPK1 and ERBB4. The study will provide significant contributions to PTC treatment. Although the effect of miR-326 on the progression of PTC was researched, it is necessary to further discover its function in tumors.

\section{References}

[1] BURKE JP, HAY ID, DIGNAN F, GOELLNER JR, ACHENBACH SJ et al. Long-term trends in thyroid carcinoma: a population-based study in Olmsted County, Minnesota, 1935-1999. Mayo Clin Proc 2005; 80: 753-758. https://doi. org/10.1016/S0025-6196(11)61529-2

[2] HODGSON NC, BUTTON J, SOLORZANO CC. Thyroid cancer: is the incidence still increasing? Ann Surg Oncol 2004; 11: 1093-1097. https://doi.org/10.1245/ASO.2004.03.066

[3] NIX P, NICOLAIDES A, COATESWORTH AP. Thyroid cancer review 1: presentation and investigation of thyroid cancer. Int J Clin Pract 2005; 59: 1340-1344. https://doi. org/10.1111/j.1368-5031.2005.00671.x

[4] JEMAL A, SIEGEL R, WARD E, HAO Y, XU J et al. Cancer statistics, 2009. CA Cancer J Clin 2009; 59: 225-249. https:// doi.org/10.3322/caac.20006

[5] MAO Y, XING M. Recent incidences and differential trends of thyroid cancer in the USA. Endocr Relat Cancer 2016; 23: 313-322. https://doi.org/10.1530/ERC-15-0445

[6] DAL MASO L, BOSETTI C, LA VECCHIA C, FRANCESCHI S. Risk factors for thyroid cancer: an epidemiological review focused on nutritional factors. Cancer Causes Control 2009; 20: 75-86. https://doi.org/10.1007/s10552-0089219-5

[7] HAUGEN BR, ALEXANDER EK, BIBLE KC, DOHERTY GM, MANDEL SJ et al. 2015 American Thyroid Association Management Guidelines for Adult Patients with Thyroid Nodules and Differentiated Thyroid Cancer: The American Thyroid Association Guidelines Task Force on Thyroid Nodules and Differentiated Thyroid Cancer. Thyroid 2016; 26: 1-133. https://doi.org/10.1089/thy.2015.0020

[8] KUNAVISARUT T. Diagnostic biomarkers of differentiated thyroid cancer. Endocrine 2013; 44: 616-622. https://doi. org/10.1007/s12020-013-9974-2

[9] SCHLUMBERGER M, SHERMAN SI. Clinical trials for progressive differentiated thyroid cancer: patient selection, study design, and recent advances. Thyroid 2009; 19: 13931400. https://doi.org/10.1089/thy.2009.1603
[10] KOJIC KL, KOJIC SL, WISEMAN SM. Differentiated thyroid cancers: a comprehensive review of novel targeted therapies. Expert Rev Anticancer Ther 2012; 12: 345-357. https://doi.org/10.1586/era.12.8

[11] HAUGEN BR. 2015 American Thyroid Association Management Guidelines for Adult Patients with Thyroid Nodules and Differentiated Thyroid Cancer: What is new and what has changed? Cancer 2017; 123: 372-381. https://doi. org/10.1002/cncr.30360

[12] AMBROS V. The functions of animal microRNAs. Nature 2004; 431: 350-355. https://doi.org/10.1038/nature02871

[13] BARTEL DP. MicroRNAs: genomics, biogenesis, mechanism, and function. Cell 2004; 116: 281-297. https://doi. org/10.1016/s0092-8674(04)00045-5

[14] PAN HW, LI SC, TSAI KW. MicroRNA dysregulation in gastric cancer. Curr Pharm Des 2013; 19: 1273-1284. https:// doi.org/10.2174/138161213804805621

[15] ZHAO LY, YAO Y, HAN J, YANG J, WANG XF et al. miR638 suppresses cell proliferation in gastric cancer by targeting Sp2. Dig Dis Sci 2014; 59: 1743-1753. https://doi. org/10.1007/s10620-014-3087-5

[16] LAI EC. Predicting and validating microRNA targets. Genome Biol 2004; 5: 115. https://doi.org/10.1186/gb-2004-59-115

[17] JI S, ZHANG B, KONG Y, MA F, HUA Y. miR-326 Inhibits Gastric Cancer Cell Growth Through Downregulating NOB1. Oncol Res 2017; 25: 853-861. https://doi.org/10.3727 /096504016X14759582767486

[18] ZHANG ZL, BAI ZH, WANG XB, BAI L, MIAO F et al. miR-186 and 326 predict the prognosis of pancreatic ductal adenocarcinoma and affect the proliferation and migration of cancer cells. PLoS One 2015; 10: e0118814. https://doi. org/10.1371/journal.pone.0118814

[19] SONG P, YIN SC. Long non-coding RNA EWSAT1 promotes human nasopharyngeal carcinoma cell growth in vitro by targeting miR-326/-330-5p. Aging (Albany NY) 2016; 8: 2948-2960. https://doi.org/10.18632/aging.101103

[20] KE J, YAO YL, ZHENG J, WANG P, LIU YH et al. Knockdown of long non-coding RNA HOTAIR inhibits malignant biological behaviors of human glioma cells via modulation of miR-326. Oncotarget 2015; 6: 21934-21949. https://doi. org/10.18632/oncotarget.4290

[21] HU Y, WANG H, CHEN E, XU Z, CHEN B et al. Candidate microRNAs as biomarkers of thyroid carcinoma: a systematic review, meta-analysis, and experimental validation. Cancer Med 2016; 5: 2602-2614. https://doi.org/10.1002/cam4.811

[22] WANG J, YANG H, SI Y, HU D, YU Y et al. Iodine Promotes Tumorigenesis of Thyroid Cancer by Suppressing Mir-422a and Up-Regulating MAPK1. Cell Physiol Biochem 2017; 43: 1325-1336. https://doi.org/10.1159/000481844

[23] WEI WT, NIAN XX, WANG SY, JIAO HL, WANG YX et al. miR-422a inhibits cell proliferation in colorectal cancer by targeting AKT1 and MAPK1. Cancer Cell Int 2017; 17: 91. https://doi.org/10.1186/s12935-017-0461-3

[24] PLOWMAN GD, GREEN JM, CULOUSCOU JM, CARLTON GW, ROTHWELL VM et al. Heregulin induces tyrosine phosphorylation of HER4/p180erbB4. Nature 1993; 366: 473-475. https://doi.org/10.1038/366473a0 
[25] TZAHAR E, WATERMAN H, CHEN X, LEVKOWITZ G, KARUNAGARAN D et al. A hierarchical network of interreceptor interactions determines signal transduction by Neu differentiation factor/neuregulin and epidermal growth factor. Mol Cell Biol 1996; 16: 5276-5287. https://doi. org $/ 10.1128 / \mathrm{mcb} \cdot 16.10 .5276$

[26] DONOGHUE JF, KERR LT, ALEXANDER NW, GREENALL SA, LONGANO AB et al. Activation of ERBB4 in Glioblastoma Can Contribute to Increased Tumorigenicity and Influence Therapeutic Response. Cancers (Basel) 2018; 10: E243. https://doi.org/10.3390/cancers10080243

[27] FLUGE O, AKSLEN LA, HAUGEN DR, VARHAUG JE, LILLEHAUG JR. Expression of heregulins and associations with the ErbB family of tyrosine kinase receptors in papillary thyroid carcinomas. Int J Cancer 2000; 87: 763-770. https://doi.org/10.1002/1097-0215(20000915)87:6<763::aidijc1>3.0.co;2-t

[28] DANYSH BP, RIEGER EY, SINHA DK, EVERS CV, COTE GJ et al. Long-term vemurafenib treatment drives inhibitor resistance through a spontaneous KRAS G12D mutation in a BRAF V600E papillary thyroid carcinoma model. Oncotarget 2016; 7: 30907-30923. https://doi.org/10.18632/oncotarget.9023

[29] CHEN J, YIN J, LIU J, ZHU RX, ZHENG Y et al. MiR202-3p functions as a tumor suppressor and reduces cell migration and invasion in papillary thyroid carcinoma. Eur Rev Med Pharmacol Sci 2019; 23: 1145-1150. https://doi. org/10.26355/eurrev_201902_17005

[30] MA Y, SUN Y. miR-29a-3p inhibits growth, proliferation, and invasion of papillary thyroid carcinoma by suppressing NF-kappaB signaling via direct targeting of OTUB2. Cancer Manag Res 2018; 11: 13-23. https://doi.org/10.2147/CMAR. S184781

[31] CAO XZ, BIN H, ZANG ZN. MiR-128 suppresses the growth of thyroid carcinoma by negatively regulating SPHK1. Biomed Pharmacother 2019; 109: 1960-1966. https://doi. org/10.1016/j.biopha.2018.08.052
[32] XU CB, LIU XS, LI JQ, ZHAO X, XIN D et al. microRNA-539 functions as a tumor suppressor in papillary thyroid carcinoma via the transforming growth factor beta1/Smads signaling pathway by targeting secretory leukocyte protease inhibitor. J Cell Biochem 2019; 120: 10830-10846. https:// doi.org/10.1002/jcb.28374

[33] KANG K, ZHANG J, ZHANG X, CHEN Z. MicroRNA-326 inhibits melanoma progression by targeting KRAS and suppressing the AKT and ERK signalling pathways. Oncol Rep 2018; 39: 401-410. https://doi.org/10.3892/or.2017.6074

[34] CAO L, WANG J, WANG PQ. MiR-326 is a diagnostic biomarker and regulates cell survival and apoptosis by targeting Bcl-2 in osteosarcoma. Biomed Pharmacother 2016; 84: 828-835. https://doi.org/10.1016/j.biopha.2016.10.008

[35] ZHANG P, KONG F, DENG X, YU Y, HOU C et al. MicroRNA-326 suppresses the proliferation, migration and invasion of cervical cancer cells by targeting ELK1. Oncol Lett 2017; 13: 2949-2956. https://doi.org/10.3892/ol.2017.5852

[36] XING M. Molecular pathogenesis and mechanisms of thyroid cancer. Nat Rev Cancer 2013; 13: 184-199. https://doi. org/10.1038/nrc3431

[37] KONDO T, EZZAT S, ASA SL. Pathogenetic mechanisms in thyroid follicular-cell neoplasia. Nat Rev Cancer 2006; 6: 292-306. https://doi.org/10.1038/nrc1836

[38] HU L, WU H, WAN X, LIU L, HE Y et al. MicroRNA-585 suppresses tumor proliferation and migration in gastric cancer by directly targeting MAPK1. Biochem Biophys Res Commun 2018; 499: 52-58. https://doi.org/10.1016/j. bbrc.2018.03.116

[39] KATO S, KOBAYASHI T, YAMADA K, NISHII K, SAWADA $\mathrm{H}$ et al. Expression of erbB receptors mRNA in thyroid tissues. Biochim Biophys Acta 2004; 1673: 194-200. https:// doi.org/10.1016/j.bbagen.2004.04.016

[40] LI M, QIAN X, ZHU M, LI A, FANG M et al. miR1273g3p promotes proliferation, migration and invasion of LoVo cells via cannabinoid receptor 1 through activation of ERBB4/PIK3R3/mTOR/S6K2 signaling pathway. Mol Med Rep 2018; 17: 4619-4626. https://doi.org/10.3892/mmr.2018.8397 